\title{
Defining Patient Centric Pharmaceutical Drug Product Design
}

\author{
Sven Stegemann, ${ }^{1,2,7}$ Robert L. Ternik, ${ }^{3}$ Graziano Onder, ${ }^{4}$ Mansoor A. Khan, ${ }^{5}$ and Diana A. van Riet-Nales ${ }^{6}$
}

Received 27 April 2016; accepted 18 May 2016; published online 17 June 2016

\begin{abstract}
The term "patient centered," "patient centric," or "patient centricity" is increasingly used in the scientific literature in a wide variety of contexts. Generally, patient centric medicines are recognized as an essential contributor to healthy aging and the overall patient's quality of life and life expectancy. Besides the selection of the appropriate type of drug substance and strength for a particular indication in a particular patient, due attention must be paid that the pharmaceutical drug product design is also adequately addressing the particular patient's needs, i.e., assuring adequate patient adherence and the anticipate drug safety and effectiveness. Relevant pharmaceutical design aspects may e.g., involve the selection of the route of administration, the tablet size and shape, the ease of opening the package, the ability to read the user instruction, or the ability to follow the recommended (inuse) storage conditions. Currently, a harmonized definition on patient centric drug development/design has not yet been established. To stimulate scientific research and discussions and the consistent interpretation of test results, it is essential that such a definition is established. We have developed a first draft definition through various rounds of discussions within an interdisciplinary AAPS focus group of experts. This publication summarizes the outcomes and is intended to stimulate further discussions with all stakeholders towards a common definition of patient centric pharmaceutical drug product design that is useable across all disciplines involved.
\end{abstract}

KEY WORDS: drug product design; patient centric; patient characteristic; product characteristic.

\section{INTRODUCTION}

People are continuously at risk of developing acute or chronic diseases that can significantly affect their lives. While the prevalence of individual diseases changes over the course of life, the majority of diseases can occur at any life stage, either alone or in conjunction with other diseases (1).

Over the past decade, tremendous progress has been made in understanding a wide range of diseases both at the genotype and phenotype levels (2). The acquired knowledge has supported the introduction of new drug therapies to improve therapeutic outcomes as well as to tackle lifethreatening diseases for which no therapy previously existed. The overall increase in life expectancy due to advances in

\footnotetext{
${ }^{1}$ Graz University of Technology, Graz, Austria.

${ }^{2}$ Capsugel, Bornem, Belgium.

${ }^{3}$ Eli Lilly and Company, Indianapolis, Indiana, USA.

${ }^{4}$ Centro Medicina dell'Invecchiamento, Department of Geriatrics, Policlinico A. Gemelli, Catholic University of the Sacred Heart, Largo Francesco Vito 1, 00168, Rome, Italy.

${ }^{5}$ Texas A\&M University, Rangel College of Pharmacy, College Station, Texas, USA.

${ }^{6}$ Medicines Evaluation Board, Utrecht, The Netherlands.

${ }^{7}$ To whom correspondence should be addressed. (e-mail: sven.stegemann@tugraz.at; )
}

pharmacotherapy, hygienic measures, healthcare, and wealth contributes to an increase in the number and type of special patient populations (3). Examples of these patients include the very old, frail and multi-morbid, the long-term cancer survivor, and the cognitively impaired (dementia). Analogous to the pediatric population, these special elderly patient populations will differ from the traditional adult population, e.g., with respect to their clinical presentation and physical, physiological, or psychological patterns. However, the collaboration and active participation of patients with common and special characteristics is one of the inevitable aspects to achieve safe and effective drug therapy and use, enabled not least by an appropriate design of the drug product.

The ability of patients to adhere to a recommended therapy may require specific skills and capabilities. When these skills and capabilities are not present, patients may alter their approach resulting in inappropriate drug use, improper administration, poor adherence, or discontinuation of medication therapy altogether. In some cases, these patients rely on support from caregivers to manage their medications. Generally, medication management becomes more demanding as the number of drug products, dosage forms, and dosing moments increases. This situation likely contributes to discrepancies in the safety and efficacy of a drug in "real" patients after product launch relative to the safety and efficacy seen in well-controlled clinical trials. 
This potential discrepancy is not surprising when one considers that most randomized clinical trials (RCT) are focused on assessing the efficacy and safety profile of drugs used to treat chronic conditions in relatively homogeneous samples of patients that often exclude patients with relevant co-morbidities, disabilities, and impairments (4). The estimation of risks and benefits of a drug treatment is therefore based on the average effects of treatments in these randomized patient populations, and is likely not inclusive of the variability in responsiveness to treatment and vulnerability to adverse effects of all patients and patient populations to whom the drug will be prescribed after approval. The resulting approved drug product may not provide the desired individual risk/benefit profile, and this risk must be considered in the overall therapeutic decision for the patient's acceptability of and success with a specific drug therapy $(5,6)$.

Knowledge in pharmacology, pharmacodynamics, pharmacokinetics, and food and drug interactions has increased as well. Consequently, user instructions (product label, package insert, and summary of product characteristics) have become more precise regarding the intended use of drug products, e.g., target age groups, dosing regimens, in-use stability, and administration approaches. A therapeutic intervention of three or more drug products is generally characterized by the use of products for multiple conditions, with each requiring a specific dosing strategy. The scheduling of such strategies may be a highly demanding task affecting the risk for dosing and administration errors. This risk is increased when restrictions or special dosing requirements are present, be such a dosing with or without food. Moreover, patients with multi-morbidity and increased healthcare needs are also at higher risk of functional and cognitive impairments, further reducing their capability in managing complex tasks (7-9).

The interface between the patient and each drug product within the holistic personal and environmental context is a critical factor in the patient's ability to follow the recommended use instructions and to realize the expected therapeutic outcome with the same risk of side effects. While the individual personal and environmental context varies from patient to patient, there are several known common traits in specific patient populations. The patient's skills, capabilities, co-morbidities, disabilities, or impairments can actually serve as predictors of potential medication problems and errors. For example, patients with significant manual dexterity impairments may not be able to break a tablet by hand $(10,11)$ or access medication in a package. Anticipating the patient characteristics of the target patient population and its subsets at the time of product design and initial development is likely to result in a drug product that addresses the needs of patients in the real world, resulting in an improved therapeutic outcome (12).

The term "patient centricity" is currently used in a variety of different contexts, e.g., communication with patients through digital platforms, exchange forums, or marketing; as a reference to patient monitoring or support systems; and in the design and execution of clinical protocols or as a descriptive word for drug products designed to meet the specific needs of individual patients and patient populations.

The objective of this publication is to promote a discussion on the definition of patient centric pharmaceutical drug product design. The authors hope to identify and present key patient, disease state, and product attributes and discuss how these attributes can affect and influence patient-product interaction. The currently proposed definition may also serve further research aimed at providing guidance to pharmaceutical scientists on the characteristics of a patient centric drug product for a specific drug product and indication.

\section{DEFINITION PROCESS}

In order to develop a definition for "patient centric pharmaceutical drug product design," a group of five experts from academia, industry and regulatory bodies, and the authors convened monthly and took a stepwise approach to develop a definition that should serve both scientific research and product development purposes.

Initial discussions revealed that several ambiguous terms were commonly used. Therefore, it was deemed necessary to align the precise meaning of these terms and words. The proposed definitions for these identified terms and words are summarized in Table I.

The term "patient centric pharmaceutical drug product design" consists of two distinct terms, "pharmaceutical drug product design" and "patient centricity." Therefore, it was deemed appropriate to first define these terms independently from each other. During the definition process of these terms, the boundaries of their definitions were clarified.

The discussions first focused on the most important and unique considerations and sought to create a short yet comprehensive one-sentence definition.

The combination of patient centricity and pharmaceutical drug product design leads to a more specific term, namely "patient centric pharmaceutical drug product design." This term describes an approach that directly aligns product characteristics with patient characteristics for a therapeutic goal in a targeted patient population(s), and requires an appropriate definition that can be used consistently among key stakeholders. The definition also addresses the requirement that human (patient) characteristics are considered in the product design. In this sense, for example, a primary package closure system should not only fulfill its functional requirement of protecting the product against environmental contamination and ensuring product stability but also incorporate requirements such as being easy to open and reclose and/or facilitating accurate dose measurement by caregivers and/or patients with limited manual dexterity, grip strength, or visual capacity.

A thorough analysis was performed to detail these items for consideration. As the analysis revealed that the identified "patient needs" were either associated with patient-related characteristics or with drug product-related characteristics, these characteristics were captured as they were discussed.

\section{PROPOSED DEFINITIONS}

The proposed one-sentence definitions of the three most frequently used terms in the patient centric pharmaceuticals discussion are summarized in Table II.

The term drug (medicine) is either used to refer to a singular therapeutic entity or as a general term for the portfolio of drug products from a specific company. The term 
Table I. Glossary of the Terms Used During the Definition Process of Patient Centric Drug Product Design

\begin{tabular}{|c|c|c|}
\hline Term & Definition & Reference \\
\hline Efficacy & $\begin{array}{l}\text { The extent to which an intervention provides benefit under ideal conditions } \\
\text { (e.g., randomized clinical settings) }\end{array}$ & Eichler et al. 2011 (6) \\
\hline Effectiveness & $\begin{array}{l}\text { The extent to which an intervention provides benefit under the usual circumstances } \\
\text { of healthcare settings (e.g., in primary care patients) }\end{array}$ & Eichler et al. 2011 (6) \\
\hline Multi-morbidity & $\begin{array}{l}\text { Co-occurrence of two or more chronic or acute diseases and medical conditions in } \\
\text { one person }\end{array}$ & Marengoni et al. 2009 (13) \\
\hline Co-morbidity & $\begin{array}{l}\text { Combination of additional diseases beyond the index condition whereby the } \\
\text { co-morbidity might affect the index disease }\end{array}$ & Marengoni et al. 2009 (13) \\
\hline Polypharmacy & The concomitant use of five or more different medicines & Nobili et al. 2011 (3) \\
\hline Impairment & $\begin{array}{l}\text { Anomalies, defects, loss, or other significant deviation in the body structure that } \\
\text { leads to a deviation from certain generally accepted population standards in the } \\
\text { biomedical status of the body and its functions }\end{array}$ & WHO 2001 (14) \\
\hline Disability & Umbrella term for impairments, activity limitations, and participation restrictions & WHO 2001 (14) \\
\hline Patient needs & $\begin{array}{l}\text { What patients—and the population as a whole-desire to receive from health care } \\
\text { services to improve overall health to provide the capacity to benefit from health } \\
\text { care services }\end{array}$ & Asadi-Lari et al. 2004 (15) \\
\hline Patient acceptability & The ability and willingness of a patient to take a medicine as intended & $\begin{array}{l}\text { EMA Paediatric Guideline } \\
2013 \text { (16) }\end{array}$ \\
\hline Dosing device & $\begin{array}{l}\text { A device or tool to measure the dose prior to or in preparation of the drug product } \\
\text { for administration (e.g., cup, dosing spoon, liquid measuring device, tablet splitter) }\end{array}$ & \\
\hline Administration device & $\begin{array}{l}\text { A device to assist in the administration of the recommended dose, e.g., dosing devices, } \\
\text { inhalation spacer, autoinjector }\end{array}$ & $\begin{array}{l}\text { EMA Paediatric Guideline } \\
2013 \text { (16) }\end{array}$ \\
\hline Medical device & $\begin{array}{l}\text { An instrument, apparatus, appliance, software, material, or other article, whether used } \\
\text { alone or in combination, intended for diagnostic and/or therapeutic purposes, e.g., } \\
\text { nebulizer system. Note: a tablet splitter is not a medical device but a dosing device. }\end{array}$ & EMA 2007 (17) \\
\hline $\begin{array}{l}\text { Comprehensive } \\
\text { assessment }\end{array}$ & $\begin{array}{l}\text { A methodology to assess patient characteristics like disease conditions, iatrogenic } \\
\text { illnesses, disabilities, impairments, polypharmacy, specific needs, and other }\end{array}$ & Onder et al. 2013 (18) \\
\hline
\end{tabular}

(drug) product relates to a specific physical presentation of the drug by a specific company. The term entails the type of dosage form and its dose/strength/concentration and excipient composition relevant to product design of the dosage form's primary, secondary, and tertiary packaging; its mode of use and dosing frequency; any potential dosing devices or medical devices; user information (product label, patient information leaflet (PIL), summary of product characteristics (SmPC); product name and appearance, both unpacked and in its primary, secondary, or tertiary packaging; and any other product- or user-related authorized information that is delivered with the product or available in digital form through the internet. For the sake of clarity, the term drug product applies to newly developed, follow on, and generic products.
In Table III, the major product- and patient-related characteristics for consideration in a patient centric pharmaceutical drug product design and development process are summarized.

Based on the definitions of "pharmaceutical drug product" and "patient centricity," a patient centric pharmaceutical drug product design spans from the basic concept of a pharmaceutical drug product to the effectiveness of the product in the hand of the patient and/or its caregivers. This drug product-patient interface includes elements that lead to the intended (re)action of the patients to use the product as intended and prevent medication non-adherence (intentional) and medication errors (unintentional). Patient centric pharmaceutical drug product design, therefore, cannot solely be based on scientific or technical theories but will have to

Table II. The Proposed One-Sentence Definition of the Three Terms

\begin{tabular}{ll}
\hline Terms & One-sentence definition \\
\hline $\begin{array}{l}\text { Pharmaceutical drug product } \\
\text { design }\end{array}$ & $\begin{array}{r}\text { The design of the comprehensive presentation of the therapeutic entity to the end user (patient/caregiver/ } \\
\text { health care provider) including the type of dosage form; formulation; dose; dosing frequency; primary, } \\
\text { secondary, and tertiary packaging; medical device; dosing devices; instructions for use (as in the SmPC/PIL/ } \\
\text { product label); and other authority-approved patient support tools and programs. } \\
\text { - The recognition of the needs of an individual patient or distinct patient populations and their specific needs } \\
\text { as the focal point in the overall design of a medicine including the targeted patients' physiological, physical, } \\
\text { psychological, and social characteristics. }\end{array}$ \\
Patient centric pharmaceutical centricity & $\begin{array}{l}\text { The process of identifying the comprehensive needs of individuals or the target patient population and } \\
\text { drug product design }\end{array}$ \\
& utilizing the identified needs to design pharmaceutical drug products that provide the best overall benefit \\
& to risk profile for that target patient population over the intended duration of treatment.
\end{tabular}


Table III. Summary of Major Drug Product-Related and Patient-Related Characteristics for Consideration in a Patient Centric Pharmaceutical Drug Product Design and Development Process

\section{Product-related characteristics}

- Type of drug substance (drug profile, desired effects, side effects, therapeutic window, mechanism of action)

- Dose to therapeutic effect (required dose range for different patient populations; need for small or larger dosing increments, dose flexibility)

- Route of administration (oral, nasal, rectal, parenteral, ...)

- Type of dosage form (tablet, capsule, solution, injection, ....)

- Formulation characteristics (immediate release, modified release, tablet size/shape/color/strength/concentration/, excipient composition, ...)

- Product strength/concentration

- Packaging (primary, secondary, tertiary)

- Dosing and administration devices (oral syringe, inhalator, ...)

- Product recognition, identification (appearance unpacked product and in its primary, secondary, or tertiary packaging name, name...)

- Instructions for use (SmPC, PIL, labeling, others....)

O Specific dosing requirements (e.g., before meal, not together with drug $x, \ldots$ )

O Product stability

O Storage conditions

$\bigcirc$ In-use shelf life and storage conditions

O Preparation steps to administration

O Compatibility with diluents and other medicines where appropriate

O Compatibility with food or drink

Industry-verified manipulations of the dosage form
Patient-related characteristics

- Developmental stage/age

O Newborn, toddler, ...

O Organ and body functions (kidney, liver, lung ...)

O Social-emotional development

Way of living (alone, with spouse, with parents)

$O$ Access to caregivers

- PK/PD and physiological changes (e.g., receptor density, kidney clearance, ...)

- Visual impairment

O Near acuity

$O$ Visual field

O Blindness

- Loss of hearing

- Swallowing impairment

O Safe solid dose swallowing

O Dysphagia

- Poor hand sensitivity

O Control of movement

Control of strength

O Sensing surfaces or temperature

C Control of eye-hand coordination

- Motoric impairment

O Grip strength

$\bigcirc$ Pinch strength

O Manual dexterity

O Arm mobility (e.g., lift above head)

O Difficulties walking

O Bedridden

- Cognitive impairment

O Mild dementia, memory loss

$\bigcirc$ Information processing speed (hearing, understanding)

- Health literacy

- Dentition

- Psychological issues

O Adherence

O Negative perception

O Depressive disorders

- Disease state, co-morbidity

O Experience of disease

$\bigcirc$ Disease cluster

O Disabilities

$\bigcirc$ End point of disease progression acknowledge the layperson's response to the product design. Therefore, testing the drug product design with the targeted patient population, within their personal health and environmental context, will be essential to developing high quality patient centric drug products. One approach to achieving this understanding would be to expand usability studies to the domiciliary setting and institutions such as schools, nurseries, etc. where appropriate. Alternatively, incorporating the ability to collect this information in the design of the clinical trial may be appropriate from certain patient populations and disease states.

By utilizing the relevant patient and disease state characteristics as well as understanding the desired therapeutic outcomes, the product designer/developer can identify rational design drivers. These design drivers, which are derived from an intimate understanding of the target patient population, can then be associated with specific design outputs that are specific to the drug product to be developed. It should be noted that the drivers and associated patient needs may be addressed or affected by one or more product design elements so that a one-to-one relationship is unlikely. Frequently, conflict among design elements arises, and decisions must be made regarding the overall risk benefit impact a particular design element may bring. This approach to the pharmaceutical drug product design can be extremely valuable in the conceptual or design phase of a new product. Table IV illustrates the relationship between design inputs, drivers, and outputs.

From Table IV, it is evident that the design drivers and design inputs have to be derived from the targeted patient 
Table IV. Summary of the Major Items Considered as Design Drivers, Their Related Design Inputs, and Respective Patient Needs

\begin{tabular}{|c|c|c|}
\hline Design Drivers & Design Inputs & Design Outputs \\
\hline Characteristics disease/condition & $\begin{array}{l}\text { - Disease-specific expression } \\
\text { - Multi- and co-morbidity } \\
\text { - Frailty } \\
\text { - Disease severity/burden } \\
\text { - Disease stage }\end{array}$ & $\begin{array}{l}\text { - Individual drug/drug combination } \\
\text { - Individual drug dose accuracy } \\
\text { - Dose range } \\
\text { - Disease-specific disabilities }\end{array}$ \\
\hline $\begin{array}{l}\text { Characteristics drug substance/ } \\
\text { physiology }\end{array}$ & $\begin{array}{l}\text { - Developmental stage (maturation, } \\
\text { declining body functions) } \\
\text { - Oro-esophageal and GI transit } \\
\text { - Permeability } \\
\text { - Fat/water ratio } \\
\text { - Drug metabolism and clearance } \\
\text { - Homeostasis } \\
\text { - Reserves }\end{array}$ & $\begin{array}{l}\text { - Flexible dose adjustment } \\
\text { - Appropriate dosage form } \\
\text { - Excipient safety/total amount of excipients } \\
\text { - Low adverse drug reactions } \\
\text { - Low intake/administration frequency }\end{array}$ \\
\hline Characteristics drug therapy & $\begin{array}{l}\text { - Need for different types of dosage forms } \\
\text { - Availability of combination products }\end{array}$ & $\begin{array}{l}\text { - Reimbursement } \\
\text { - Dose tracking }\end{array}$ \\
\hline Characteristics drug product & $\begin{array}{l}\text { - Multiple and polypharmacy } \\
\text { - Therapeutic complexity } \\
\text { - Prescription guidelines } \\
\text { - Different dosage forms } \\
\text { - Possibility of product modifications } \\
\text { (manipulations) } \\
\text { - Range of trademarks }\end{array}$ & $\begin{array}{l}\text { - Simplified regimen } \\
\text { - Appropriate dosage form } \\
\text { - Drug product identification } \\
\text { - Drug product recall } \\
\text { - Dosing frequency } \\
\text { - Dosing moments } \\
\text { - Dispensing, substitution, and re-substitutions } \\
\text { - Reimbursement } \\
\text { - Dose tracking }\end{array}$ \\
\hline Patient characteristics & $\begin{array}{l}\text { - Age, gender, socio-emotional development } \\
\text { - Mobility (travel) } \\
\text { - Perceived wellbeing } \\
\text { - Functional limitations (motoric, sensory, } \\
\text { cognitive) } \\
\text { - Health literacy (disease/therapy } \\
\text { understanding) } \\
\text { - Dehydration/malnutrition } \\
\text { - Motivation } \\
\text { - Psychological traits } \\
\text { - Remaining life time } \\
\text { - Living alone or with others } \\
\text { - Daily occupation (work, school) } \\
\text { - Social support and interaction } \\
\text { - Stress resistance }\end{array}$ & $\begin{array}{l}\text { - Usability/ergonomics } \\
\text { - Self-explaining/intuitive use } \\
\text { - Drug product information } \\
\text { - Product identification } \\
\text { - Swallowability } \\
\text { - Palatability (taste, smell, texture) } \\
\text { - Reminder } \\
\text { - Dosing frequency/moments } \\
\text { - Least number of units/drug products } \\
\text { - Feedback/communication/motivation }\end{array}$ \\
\hline $\begin{array}{l}\text { Medication management } \\
\text { (adherence and administration) }\end{array}$ & $\begin{array}{l}\text { - Intended and non-intended non-adherence } \\
\text { - Therapy simplification } \\
\text { - Pill boxes and compliance aids } \\
\text { - Hoarding } \\
\text { - Environment where the medication needs } \\
\text { to be prepared and taken } \\
\text { - Access/cost } \\
\text { - Co-medications and changing (generic) } \\
\text { prescriptions }\end{array}$ & $\begin{array}{l}\text { - Identification/differentiation outside packaging } \\
\text { - Dosing frequency/moments } \\
\text { - In-use stability (e.g., external "pill box," } \\
\text { airport scanning) } \\
\text { - Ease of storage } \\
\text { - Convenience of use (e.g., specific requirements } \\
\text { like before breakfast) } \\
\text { - Use discretion } \\
\text { - Portability } \\
\text { - Food effects } \\
\text { - Refill reminders } \\
\text { - Harmonized labeling, naming elements, } \\
\text { product elements (e.g., packaging), or cue tags }\end{array}$ \\
\hline $\begin{array}{l}\text { Usability (handling, storage, } \\
\text { and disposal) }\end{array}$ & $\begin{array}{l}\text { - Drug product appearance } \\
\text { - Drug product shelf life } \\
\text { - Drug product storage } \\
\text { - Drug product disposal } \\
\text { - Drug product packaging } \\
\text { - Dose measurement and preparation } \\
\text { - Dosing frequency } \\
\text { - Need for administration device } \\
\text { - Ability to self-administer with ease } \\
\text { - Need for help from caregiver } \\
\text { - Learned usage/experience }\end{array}$ & $\begin{array}{l}\text { - Handling issues (e.g., round tablets roll off the table) } \\
\text { - Ergonomics } \\
\text { - Formulations enabling (easier) self-administration } \\
\text { - Refrigeration requirements } \\
\text { - Stability during use period } \\
\text { - Minimize waste (dose form, packaging) } \\
\text { - Mechanical stress stability of the product } \\
\text { - "Predicted usage" (modification by patient) }\end{array}$ \\
\hline
\end{tabular}


population. Comprehensive assessments (e.g., comprehensive geriatric assessments) are a key part in generating and prioritizing the patient population-specific design drivers and design inputs. This process requires the involvement of different healthcare professionals (e.g., physicians, nurses, caregivers, and pharmacists) in performing the assessment and identifying the most important and appropriate design outputs together with the concerned patient population (18).

For example, medicine $M$ with active substance $S$ is marketed by a company $C$ as four drug products: an immediate release tablet $100 \mathrm{mg}, 200 \mathrm{mg}, 400 \mathrm{mg}$ with a break mark, and an oral solution $20 \mathrm{mg} / \mathrm{ml}$. The initial dose is 20 to $60 \mathrm{mg} /$ day for children from birth up to 5 years of age; $100 \mathrm{mg} /$ day for children from 5 years; and $200 \mathrm{mg}$ once or twice daily for adults. The maintenance dose is $10-20 \mathrm{mg} / \mathrm{kg}$ in several doses for all patient populations. The maximum dose is $35 \mathrm{mg} / \mathrm{kg}$ /day for children up to 6 years, $100 \mathrm{mg} /$ day for children from 6 years old and $1200 \mathrm{mg}$ for adults, all in several doses. The four drug products enable all recommended doses. However, it can be questioned if the specific needs of individual patients are sufficiently addressed by this portfolio, as an older person with swallowing difficulties in need of the maximum dose would need to take 20 -ml solution thrice daily. A solution with a higher strength or a multiparticulate formulation may further support the medicine's patient centric approach.

The oral solution is packed in a $100-\mathrm{ml}$ brown glass bottle with a closure that can be attached to an oral syringe as the primary packaging. The solution is water-based. Besides the active substance $S$, it contains a sweetener, preservative, flavor, and colorant. The bottle is labeled and stored in a carton box as the secondary packaging. The label on the glass bottle and outer box each carries the main product information like name, drug substance, dose/strength/concentration, indication, expiry date, and storage condition. The detailed product information is captured in the PIL, and a paper version of the PIL is packed with the glass bottle in the outer carton box. The outer packaging does not include a dosing device. Pharmacists are held responsible for delivering a dosing device that allows accurate dosing of the individual patient's dose. Links to additional product information either through a web site of a bar code APP might be printed on the PIL or the box. Patients would benefit from information on the potential of tablet chewing, mixing, or crushing and the joint intake with food or drink as these approaches may avoid the intake of high volumes of the oral solution in patients with swallowing difficulties

The concept of patient centricity intends to consider all elements of product design affecting or addressing the specific needs of the target patient population. These elements can be derived from known patient characteristics including age, comorbidities, and functional limitations at the various stages of the disease. Even though the specific expression and progression of a given disease may vary among individual patients, the major disease effects, particularly at more advanced stages of a disease, are normally quite similar. Main effects are typically manifest in the sensory, motoric, cognitive, and psychological domains and present in a similar way. For example, cluster analysis provided evidence that patients with hypertension suffer most from heart failure, atrial fibrillation, and cerebrovascular disease, while patients with diabetes mellitus have a high likelihood for visual impairments and deafness as co-morbidity (13). These predictable diseases and patient-specific characteristics can be leveraged to improve the drug product design by utilizing a "patient centric" development approach.

\section{DISCUSSION}

The principles of patient centricity are being used in conjunction with and to augment various healthcare interventions dedicated to improving their effectiveness for patients. When considering the role of pharmacotherapy in healthcare interventions, it is evident that the patient-drug product interface is a critical part of the therapeutic process that might lead to medication non-adherence or medication errors (19). To achieve the desired outcome, patient factors need to be considered and incorporated into the product design. For medical devices, human factor studies are now required to be incorporated into the development process to ensure the device is able to be effectively used by the patient or caregiver, and potential sources of use errors are minimized (20). Drug products resulting from a "patient centric development approach" must aim to enhance the usability of the drug products supporting the medicine's safety, effectiveness, and quality over the entire target patient population.

The effective use of drug products over the course of treating a disease requires certain levels of disease understanding, therapeutic strategies, treatment requirements, and patient or caregiver capabilities. These levels of understanding and capability can be divided into skill-, rule-, and knowledge-based information, and task processing. The skill-based level refers to highly practiced and familiar tasks that require only very little attention and are to a great extent automatic behavior. The rule-based level requires some consciousness as the information or task has to be derived from a known rule that needs to be applied to the situation. In cases where the information or task is new and no rules can be applied, the task becomes knowledge-based, requiring a higher level of capability to manage the unfamiliar situation by identifying analogies with previous experience or use higher-level knowledge and feedback from the environment (21). While skill-based tasks are the lowest cognitive and functionally demanding tasks, they are sensitive to errors due to strong habitual processing, inappropriate reactions to changes as well as resistance to change. In contrast to this, knowledge-based tasks generate errors through excessive demand and stress, as well as lack of knowledge or awareness of the consequences. Errors occurring in skill-based tasks are mainly "slips" or "lapses," coming from a correct intention but a failure when carrying out the task, while "mistakes" arise from an incorrect intention leading to a wrong sequence of activities due to application of an inappropriate rule or lack of knowledge (22). In the typical situation, many patients may need to take several drugs at the same moment, which raises the level of demand from skill-based to more rule- or knowledge-based tasks. With the varying health literacy of patients (23), the effective delivery of the relevant product information to the patient is a critical part of a patient centric pharmaceutical drug product design and has to be looked at from different patient characteristics $(24,25)$. The patient's general physician, medical doctor, pharmacist, nurse, or 
professional caregiver all play a key role in selecting the most suited pharmaceutical drug product to assure the optimal interaction between the patient and the product that ensures safe drug product administration and effective therapy. This includes an integral approach to formulation development, which also takes account of product access, reimbursement, etc. The prescription of patient centric products will have to take into account the concurrent use of other products to reduce the risk of confusion. Finally, frequent monitoring of the patient's behavior is required in order to provide essential and continuing education and assurance that the drug product is being used as intended.

The European Medicines Agency (EMA) defines a drug product as "a pharmaceutical preparation in its container closure system, together with any measuring and administration device and the authorized written user instructions (SmPC section 6, package leaflet, product label)." This definition is extended by additional terms specifying the preparation as being "a formulation in a particular strength/ concentration," or in case of formulations for single use, the labeled container contents and a formulation as being "the composition of a particular dosage form." Although not specified, the formulation also entails the product appearance. Furthermore, the EMA provides a definition of "pharmaceutical design of a drug (medicine)" as "the composition, dosage form, route of administration, dosing frequency, packaging, measuring or administration device and the user instruction of a medicine." The currently proposed definitions are in agreement with those of the EMA, yet they provide a stronger emphasis on the interaction between the patient and the drug product.

The closest regulatory definition combining product and patient aspects is the definition used for "age appropriate paediatric drug (medicine)" which is "a drug (medicine), whose pharmaceutical design makes it suitable for use in the target age group(s)" (26). This definition, however, focuses on the product usability. However, the definition does not make clear if the suitability of use would also relate to the entire patient-product interface that should assure the intended and correct use, including prevention of non-adherence (intentional) or medication errors (unintentional).

There is no clear definition for patient centricity even though the words are used in several contexts. The common theme is that patient centric means the involvement of the patient in the healthcare process. The FDA uses patient centricity as a term in conjunction with "Patient Reported Outcomes," which aims to get patient feedback on the benefit to risk of a new drug substance in the development process and the perceived value for the patient (27). The definition proposed by the authors puts patient centricity in the context of the pharmaceutical drug product design, through the direct involvement of the patients in the conceptual phase of the development of the drug and the re-evaluation of the drug's pharmaceutical design during the marketing phase for potential product enhancements during the product life cycle.

In principle, the development of a patient centric drug product may follow similar processes as being used for the development of medical devices or healthcare environments $(28,29)$. This would include a user and use environment profiling, cognitive walkthrough and task analysis, risk analysis as well as usability testing in the concerned patient population. The process targets to identify product-related sources of medication errors or issues that would have an impact on drug product safety and effectiveness. For example, a drug product that needs to be taken in the fasted state at least half an hour before breakfast has a high likelihood in certain patients to be taken after breakfast along with the other medications unless the drug product is designed in a way that "forces" patients to an administration before breakfast. Valuable information on product characteristics and how they relate to the patient-product interaction can be generated from other methodologies applied during drug product design and development. Leveraging information from product design studies incorporating multiple prototypes, as well as subsequent usability and human factors studies will undoubtedly result in improved products for patients and caregivers. Patient-reported outcome (PRO) studies, aiming to capture patient feedback on the perception and experience with a drug treatment in the relevant disease $(30,31)$ is an emerging area of focus that will increasingly provide greater insight into product design. Ethnography (32) and ergonomic research (33) are other tools that can be used during the development of pharmaceutical products. The consumer healthcare industry has a tradition in involving consumers and patients in the drug product development process through patient testing and consumer surveys (34), and the consumer industry in general has introduced "design thinking" as a process to better address the consumer needs in product design $(35,15)$. Technical specifications and standards exist for testing the ease of opening of consumer packaging (CEN/TS 15945) or child resistance (ISO 8317:2015) that provide useful insight into usability aspects. For pharmaceutical applications, traditional customer centric approaches may need to be adapted to provide greater relevance to the specific needs of the patient population for a given product. Additional valid methods are required and might be developed based in the existing methods and the learnings from other industries to provide the necessary comparison between and evidence for patient centric drug product design.

This approach to achieving a patient centric pharmaceutical drug product design is also in agreement with the principles used for establishing patient safety in healthcare environment (36), and FDA's quality by design approach for enhanced product and process understanding leading to the development of pre-defined drug products with desired therapeutic outcomes (12). US FDA has long recognized that quality cannot be tested into compliance of a drug product, and the drug product needs to have a well-defined target product profile with specific patient need documentation ahead of product development. This strategy ensures that the drug product and process are well understood to consistently deliver the pre-defined performance to the specific patient population. Therefore, the regulatory precedence for patient centric dosage forms is in place, although it is not well defined and promoted. One such example of a patient centric dosage forms for geriatric use is the approval of $3 \mathrm{D}$ printed Spritam $\AA$ tablet dosage forms that are designed for easy swallowability of even up to 1250-mg dose of levetiracetam. This drug product was approved by US FDA in August 2015. Spritam $\AA$ tablets disintegrate within seconds when taken with a sip of water, to provide medication in an 
easily swallowable mass in the mouth of geriatric patients, or even other patients that have difficulty in swallowing. Taking into account that expressions of many age- and diseaserelated design drivers and design inputs are similar, it can be hypothesized that the design outputs will serve several patient populations as well as not exclude any patients with less severe expressions. This means that patient centric pharmaceutical drug product design will become self-evident, make the products more universal, and eventually, provide improved standards. These expected outcomes will lead to enlarged rather than restricted patient populations that benefit from such patient centric design.

It should be noted that patient centricity might also include quality aspects mainly required for industrial and regulatory purposes, but that may not be a direct need for the patient. For example, a 2-5-year stability of the drug product is commonly targeted to assure the industrial supply chain and hence patient access to the drug product. However, a patient would only require product stability during the time of product receipt and treatment duration, which is normally no longer than 3 months for in-use conditions. In this respect, a long shelf life remains primarily a supply chain need and not a direct need of the patient even though the patient might benefit indirectly from a long shelf life.

\section{CONCLUSION}

Drug products are becoming increasingly diverse whereas the therapeutic dosing regimens that have to be adopted by the main users of drugs may become rather complex. In order to adequately address medication management in future drug therapies, the interface between a drug product and an individual patient has to be considered a critical part of product quality and an important condition to the drug's intended use and hence its benefit to risk profile. A patient centric drug product aims to reduce medication errors while improving the medicine's effectiveness through a usercentered product design of the portfolio of drug products that is based on a prediction and subsequent evaluation of the interface of the patient or caregiver with the product that is mainly intended to serve the needs of this patient. For the future scientific research in this area, it is important to have a clear definition of patient centric pharmaceutical drug product design and its implementation in drug product development. The current publication can be used as a basis for further discussions among the relevant stakeholders. It may further highlight the need to better inform patients, caregivers, and healthcare professionals on the characteristics of the drug products in the overall drug portfolio and the advantages and disadvantages associated with the use of any such product.

\section{ACKNOWLEDGMENTS}

Open access funding provided by Graz University of Technology. The authors would like to thank the members of the AAPS Patient Centric Drug Development, Drug Product Design, and Manufacturing Focus Group (PCFG): Gerard
McNally (McNeil Consumer Healthcare, Fort WA, USA), David Harris (Merck, Kenilworth, USA), Alfred Rumondor (Merck, Kenilworth, USA), Melissa A. Keeney (Eli Lilly, Indianapolis, USA), Carrie J. Smith (Eli Lilly, Indianapolis, USA), Weiguo Dai (Johnson \& Johnson, Rariten, USA), and Robert Becker (Impala Pharma, Munich, Germany) for the fruitful discussions and contributions to this paper.

\section{COMPLIANCE WITH ETHICAL STANDARDS}

Conflict of Interest Diana A. van Riet-Nales is a senior assessor at the Medicines Evaluation Board in the Netherlands (MEB) and a member of the European Medicine Agency's (EMA) Quality Working Party (QWP). The views expressed in this publication are those of the author only and should neither be considered as the view of the MEB or EMA nor any of their working parties or committees. Similarly, Mansoor Khan has served as one of the directors in CDER/FDA for more than 11 years. The views expressed by him should not be construed as the official position of the FDA.

Open Access This article is distributed under the terms of the Creative Commons Attribution 4.0 International License (http://creativecommons.org/licenses/by/4.0/), which permits unrestricted use, distribution, and reproduction in any medium, provided you give appropriate credit to the original author(s) and the source, provide a link to the Creative Commons license, and indicate if changes were made.

\section{REFERENCES}

1. Murray CJL, Vos T, Lozano R, Naghavi M, Flaxman AD, et al. Disability-adjusted life years (DALYs) for 291 diseases and injuries in 21 regions, 1990-2010: a systematic analysis for the Global Burden of Disease Study 2010. Lancet. 2012;380:2197223.

2. Gustafsson M, Nestor CE, Zhang H, Barabasi A-L, Baranzini S, et al. Modules, networks and systems medicine for understanding disease and aiding diagnosis. Genome Med. 2014;6:82.

3. Nobili A, Marengoni A, Tettamanti M, Salerno F, Pasina L, Franchi $\mathrm{C}$, et al. Association between clusters of diseases and polypharmacy in hospitalized elderly patients: results from REPOSI study. Eur J Int Med. 2011;22:597-602.

4. Cerreta F, Eichler H-G, Rasi G. Drug policy for an aging population-the European Medicines Agency's geriatric medicines strategy. N Engl J Med. 2012;367(21):1972-4.

5. Tinetti ME, Studenski SA. Comparative effectiveness research and patients with multiple chronic conditions. N Eng J Med. 2011;364(26):2478-81.

6. Eichler H-G, Abadie E, Breckenridge A, Flamion B, Gustafsson LL, Leufkens $\mathrm{H}$, et al. Bridging the efficacy-effectiveness gap: a regulator's perspective on addressing variability of drug response. Nat Rev Drug Disc. 2011;10:495-506.

7. Boyd CM, Wolff JL, Giovannetti E, Reider L, Weiss C, Xue Q, et al. Healthcare task difficulty among older adults with multimorbidity. Med Care. 2014;52:S118-25.

8. Stenholm S, Westerlund H, Head J, Hyde M, Kawachi I, Pentti J, et al. Comorbidity and functional trajectories from midlife to old age: the health and retirement study. J Gerontol A Biol Sci Med Sci. 2015;70(3):330-6.

9. Ehlenbach WJ, Larson EB, Curtis JR, Hough CL. Physical function and disability after acute care and critical illness hospitalization in a prospective cohort of older adults. J Am Geriatr Soc. 2015;63(19):2061-9. 
10. Atkin PA, Finnegan TP, Ogle SJ, Shenfield GM. Functional ability of patients to manage medication packaging: a survey of geriatric inpatients. Age Ageing. 1994;23:113-6.

11. Carmeli E, Patish H, Coleman R. The aging hand. J Gerontol Med Sci. 2003;58A(2):146-52.

12. ICH Q8(R2). Pharmaceutical development. 2009 (http:// www.ich.org/fileadmin/Public_Web_Site/ICH_Products/Guidelines/Quality/Q8_R1/Step4/Q8_R2_Guideline.pdf).

13. Marengoni A, Rizzuto D, Wang HX, Winblad B, Fratiglioni L. Patterns of multimorbidity in the elderly population. J Am Geriatr Soc. 2009;57:225-30.

14. WHO: The International Classification of Functioning, Disability and Health: World Health Organization Resolution WHA 54.21. http://www.who.int/classification/icf/en/ (2001).

15. Asadi-Lari M, Tamburini M, Gray D. Patients' needs, satisfaction, and health related quality of life: towards a comprehensive model. Health Qual Life Outcome. 2004;2:32.

16. EMA: Guideline of pharmaceutical development of medicines for paediatric use. EMA/CHMP/QWP/805880/2012 Rev. 2. http:// www.ema.europa.eu/docs/en_GB/document_library/ Scientific_guideline/2013/07/WC500147002.pdf (2013).

17. EMA: European Medical Devices Directive - 93/42/EEC with 2007/47/EC. http://eurlex.europa.eu/ LexUriServ.do?CONSLEG:1993L0042:20071011:eng:PDF (2007).

18. Onder G, van der Cammen TJM, Petrovic M, Somers A, Rajkumar C. Strategies to reduce the risk for iatrogenic illness in complex older adults. Age Ageing. 2013;42:284-91.

19. Reason J. Human error: models and management. BMJ. 1990;320:768-70.

20. FDA. Draft guidance for industry and food and drug administration staff. Applying human factors and usability engineering to optimize medical device design. 2011 (UCM259748).

21. Rasmussen J, Vicente KJ. Coping with human errors through system design: implications for ecological interface design. Int J Man-Mach Stud. 1989;31:517-34.

22. Aronson JK. Medication errors: what they are, how they happen, and how to avoid them. Q J Med. 2009;102:513-21.

23. Greenhalgh T. Health literacy: towards system level solutions. BMJ. 2015;350:h1026.

24. Wong PK, Christie L, Johnston J, Bowling A, Freeman D, Joshua $\mathrm{F}$, et al. How well do patients understand written instructions? Health literacy assessment in rural and urban rheumatology outpatients. Medicine. 2014;93(25), e129.

25. Mullen E. Health literacy challenges in the aging population. Nurs Forum. 2013;48(4):248-55.

26. EMA. Guideline on pharmaceutical development of medicines for paediatric use. 2011/06/WC500107908

27. FDA. Guidance for industry. Patient-reported outcome measures: use in medical product development to support labeling claims. 2009 UCM 193282

28. Fisk AD, Rogers WA, Charness N, Czaja SJ, Sharit J. Designing for older adults. Principles and creative human factors approaches. Boca Raton: CRC Press; 2009. ISBN 978-1-42008055-1.

29. Carayon P, editor. Human factors and ergonomics in health care and patient safety. Boca Raton: CRC Press; 2012. 978-1-43983033-8.

30. Rothman M, Burke L, Erickson P, Kline Leidy N, Patrick CL, Petrie CD. Use of existing patient-reported-outcome (PRO) instruments and their modification: the ISPOR good research practices for evaluating and documenting content validity for the use of existing instruments and their modification PRO task force report. Value Health. 2009;12(8):1075-83.

31. Reeve BB, Wyrwich KW, Wu AW, Velikova G, Terwee CB, Snyder CF, et al. ISOQOL recommends minimum standards for patient-reported outcome measures used in patient-centered outcomes and comparative effectiveness research. Qual Life Res. 2013;22:1889-905.

32. Goodson L, Vassar M. An overview of ethnography in healthcare and medical education. J Educ Eval Health Prof. 2011;8:4.

33. Ehmen H, Haesner M, Steinke I, Dorn M, Gövercin M, Steinhagen-Thiessen E. Comparison of four different mobile devices for measuring heart rate and ECG with respect to aspects of usability and acceptance by older people. Appl Ergon. 2012;43:582-7.

34. Hellier E, Tucker M, Kenny N, Rowntree A, Edworthy J. Merits of using color and shape differentiation to improve the speed and accuracy of drug strength identification on over-the-counter medicines by laypeople. J Patient Saf. 2010;6:158-64.

35. Beckman SL, Barry M. Innovation as a learning process: embedding design thinking. Calif Manag Rev. 2007;50(1):25-56.

36. WHO. Conceptual framework for the international classification for patient safety. $2009 \mathrm{WHO} / \mathrm{IER} / \mathrm{PSP} / 2010.2$ 